\title{
Practice advisory update summary: Patent foramen ovale and secondary stroke prevention
} Report of the Guideline Subcommittee of the American Academy of Neurology

Steven R. Messé, MD, Gary S. Gronseth, MD, David M. Kent, MD, MSc, Jorge R. Kizer, MD, MSc, Shunichi Homma, MD, Lee Rosterman, DO, John D. Carroll, MD, Koto Ishida, MD, Navdeep Sangha, MD, and Scott E. Kasner, MD, MSCE

Neurology ${ }^{\circledR} 2020 ; 94: 876-885$. doi:10.1212/WNL.0000000000009443

\section{Abstract}

\section{Objective}

To update the 2016 American Academy of Neurology (AAN) practice advisory for patients with stroke and patent foramen ovale (PFO).

\section{Methods}

The guideline panel followed the AAN 2017 guideline development process to systematically review studies published through December 2017 and formulate recommendations.

\section{Major recommendations}

In patients being considered for PFO closure, clinicians should ensure that an appropriately thorough evaluation has been performed to rule out alternative mechanisms of stroke (level B). In patients with a higher risk alternative mechanism of stroke identified, clinicians should not routinely recommend PFO closure (level B). Clinicians should counsel patients that having a PFO is common; that it occurs in about 1 in 4 adults in the general population; that it is difficult to determine with certainty whether their PFO caused their stroke; and that PFO closure probably reduces recurrent stroke risk in select patients (level B). In patients younger than 60 years with a PFO and embolic-appearing infarct and no other mechanism of stroke identified, clinicians may recommend closure following a discussion of potential benefits (absolute recurrent stroke risk reduction of $3.4 \%$ at 5 years) and risks (periprocedural complication rate of $3.9 \%$ and increased absolute rate of non-periprocedural atrial fibrillation of $0.33 \%$ per year) (level C). In patients who opt to receive medical therapy alone without PFO closure, clinicians may recommend an antiplatelet medication such as aspirin or anticoagulation (level C).

\author{
Correspondence \\ American Academy of \\ Neurology \\ guidelines@aan.com
}

\section{MORE ONLINE}

\section{ค Podcast}

Dr. Andrew Southerland talks with Dr. Steven Messé about his practice advisory update paper on patent foramen ovale and secondary stroke prevention. NPub.org/c6d96m 


\section{Glossary}

AAN = American Academy of Neurology; $\mathbf{C I}=$ confidence interval; COIs = conflicts of interest; CTA = CT angiography; DOAC $=$ direct oral anticoagulant; GRADE = Grading of Recommendations Assessment, Development and Evaluation; GS = Guideline Subcommittee; HR = hazard ratio; MRA = MR angiography; NT-proBNP = N-terminal pro b-type natriuretic peptide; $\mathbf{P F O}=$ patent foramen ovale; $\mathbf{R D}=$ risk difference; $\mathbf{R R}=$ risk ratio; $\mathbf{S G S}$ = symmetric Gauss-Seidel; $\mathbf{T C D}=$ transcranial Doppler ultrasonography; TEE = transesophageal echocardiography; TTE = transthoracic echocardiography.

The American Academy of Neurology (AAN) published a practice advisory in 2016 regarding secondary stroke prevention in patients with patent foramen ovale (PFO). ${ }^{1}$ Additional randomized trials have since been published, and the Food and Drug Administration approved the AMPLATZER PFO Occluder and GORE CARDIOFORM Septal Occluder for use in the United States, necessitating an update. The clinical questions remain unchanged:

- In patients with a PFO who have had an otherwise cryptogenic ischemic stroke, does percutaneous PFO closure reduce the risk of stroke recurrence compared with medical therapy alone?

- In patients with a PFO who have had an otherwise cryptogenic ischemic stroke, does anticoagulation reduce the risk of stroke recurrence compared with antiplatelet medication?

This update does not address management of stroke risk factors or causes aside from PFO.

\section{Description of the analytic process}

This update summary (see full-length update at aan.com/ Guidelines/home/GetGuidelineContent/992) follows the 2017 AAN guideline development process. ${ }^{2}$ In April 2018, the AAN Guideline Subcommittee (GS) convened an author panel of neurologists, internists, and cardiologists with expertise in stroke and PFO. All authors were reviewed by AAN staff and GS leadership for financial and intellectual conflicts of interest (COIs). A majority of the author panel (S.R.M., G.S.G., S.H., K.I., D.M.K., L.R., and N.S.) are free of COIs relevant to the subject matter of this practice advisory. The systematic literature review was performed by the lead author (S.R.M.), AAN methodologist (G.S.G.), and members of the GS, who had no COIs. MEDLINE and the Cochrane Library were searched to identify randomized studies published between March 2015 and August 2019 pertinent to the clinical questions. Studies were independently rated for their risk of bias by the AAN methodologist (G.S.G.) and lead author (S.R.M.).

Consistent with previous AAN guidelines on this topic, the primary outcome of interest was recurrent stroke. The panel used study-reported, procedure-related serious adverse events and non-periprocedural atrial fibrillation, variously defined across studies, as the primary safety outcomes.
Transient periprocedural atrial fibrillation is of uncertain clinical consequence following catheter-based cardiac procedures and generally does not lead to long-term anticoagulation or high risk of stroke. To minimize bias, the panel relied on intention-to-treat analyses to inform conclusions. For the primary summary analysis, the panel used studies with the lowest risk of bias and excluded studies of devices that are not being manufactured and are not available.

Ratio measures were pooled by meta-analyses to obtain summary estimates of effect. Because of low event rates, hazard ratios (HRs), risk ratios (RRs), and odds ratios were considered comparable. For pooling effect sizes, a randomeffects meta-analytic model was desired because of the substantive heterogeneity between studies in closure devices, inclusion and exclusion criteria, and medical treatments. However, standard inverse-variance methods can have poor statistical coverage when event rates are low, ${ }^{3}$ such as with the PFO closure trials. In addition, non-inverse-variance random-effects methods appropriate for studies of rare events have poor precision when the number of studies is low. ${ }^{4}$ Thus, for the primary efficacy analysis of recurrent stroke, the panel selected a hybrid approach for meta-analysis ${ }^{5}$ : a fixed-effect model for hypothesis testing of a treatment effect using inverse-variance methods to pool HRs and a random-effects model of RRs designed for low event rates (the weighted symmetric Gauss-Seidel [sGS] algorithmic method $^{6}$ ) to explore heterogeneity of effect sizes. Sensitivity analyses were performed to determine the effect of including trials with a higher risk of bias and trials that used devices that are not available. Additional sensitivity analyses were performed to compare the effect of different meta-analytic techniques. To improve clinical interpretability, the panel calculated risk differences (RDs) or rate differences from pooled RRs and baseline recurrent stroke risk from the nonclosure arms of the included studies. Prespecified subgroups of interest included age, shunt size (as defined by each study), presence of atrial septal aneurysm (as defined by each study), antithrombotic management (antiplatelet vs anticoagulation) in patients who are medically treated, and whether the index stroke appeared embolic (e.g., not a single, small, and subcortical infarct in the distribution of a perforator artery).

The overall confidence in the evidence was determined using a modified Grading of Recommendations Assessment, 
Development and Evaluation (GRADE) approach. ${ }^{2,7,8}$ The panel then derived recommendations using an iterative modified Delphi process after considering the evidence strength, risks and benefits, cost, availability, and patient preference variations.

\section{Analysis of evidence}

The initial literature search identified 628 unique articles, of which 8 met the inclusion criteria, including 1 article that provided extended follow-up from a trial that had been included in the previous practice advisory. ${ }^{1}$

\section{In patients with a PFO who have had a cryptogenic ischemic stroke, does percutaneous PFO closure reduce the risk of stroke recurrence compared with medical therapy alone?}

\section{Evidence}

The 2016 practice advisory included 3 studies. ${ }^{9-11}$ The current classification of evidence scheme for therapeutic studies ${ }^{2}$ downgraded each to Class II because participants and their caregivers were unblinded to treatment assignment and actual treatment received and, for most studies, initial end point ascertainment was unblinded.

The CLOSURE I study (Class II) was a multicenter, randomized, open-label trial of 909 participants aged 18-60 years with PFO and a cryptogenic stroke or TIA (all other studies discussed only included patients with stroke) that compared the STARFlex percutaneous closure device (NMT Medical, Inc.) with medical therapy alone and observed the participants for a median of 2 years. ${ }^{9}$ Recurrent stroke occurred in $2.9 \%$ of participants who underwent closure and in $3.1 \%$ of those receiving medical therapy alone ( $\mathrm{RD}-0.2 \%, 95 \%$ confidence interval $[\mathrm{CI}],-2.5 \%$ to $2.1 \%)$. The rate of serious non-periprocedural atrial fibrillation was not different between groups, with a rate difference of $0.7 \%$ per year $(95 \% \mathrm{CI}$, $-0.07 \%$ to $1.6 \%$ per year), and major procedural complications were reported in $3.2 \%$ (95\% CI, 1.9\%-5.5\%).

The PC Trial (Class II) randomized 414 participants younger than 60 years to medical therapy or closure with the AMPLATZER PFO Occluder (Abbot, Inc.) and observed them for an average of 4 years. ${ }^{10}$ There was no significant difference in stroke recurrence, with a rate difference of $-0.48 \%$ per year ( $95 \% \mathrm{CI},-1.2 \%$ to $0.12 \%$ ) for participants who underwent closure compared with participants assigned to medical therapy. New-onset non-periprocedural atrial fibrillation was not different between trial arms, with a rate difference of $0.1 \%$ per year ( $95 \% \mathrm{CI},-0.58 \%$ to $0.58 \%$ ), and major procedural complications were reported in $1.5 \%(95 \%$ CI, $0.5 \%-4.2 \%)$.

In the RESPECT trial (Class II), 980 participants aged 18-60 years were randomized to the AMPLATZER PFO
Occluder (St. Jude Medical, Inc.) or medical therapy consisting of antiplatelet medication or anticoagulation. ${ }^{11}$ The median duration of follow-up was 2.1 years. In the intention-to-treat analysis, recurrent stroke was reported in 9 of 499 (1.8\%) participants assigned to device closure compared with 16 of 481 (3.3\%) in the medical arm (rate difference $-0.70 \%$ per year, $95 \% \mathrm{CI},-1.56 \%$ to $0.08 \%$ per year).

Four new articles met the inclusion criteria, of which 3 are Class II and 1 Class III for risk of bias. The RESPECT trial (Class II) continued to follow participants beyond the first prespecified analysis, for a median of 5.9 years. ${ }^{12}$ This was the third analysis from this trial, and only these updated data were included in the summary of effects discussion of this guideline. Recurrent strokes occurred in 28 participants randomized to medical therapy and 18 participants assigned to closure (rate difference $-0.47 \%$ per year, $95 \%$ CI, $-0.97 \%$ to $-0.01 \%$ per year). The rates of new-onset non-periprocedural atrial fibrillation were not different, comparing participants receiving closure with those receiving medical treatment, with a rate difference of $0.14 \%$ ( $95 \%$ CI, $-0.2 \%$ to $0.49 \%$ ). Procedural complications occurred in 5\% (95\% CI, 3.4\%-7.3\%). Of note, pulmonary embolism was reported to be more common after closure ( $0.41 \%$ per year in the PFO closure arm and $0.11 \%$ per year in the medical arm, HR 3.48; 95\% CI, 0.98-12.34; $p=0.04)$, and deep vein thrombosis was numerically more common as well $(0.16 \%$ per year in the closure arm and $0.04 \%$ per year in the medical arm, HR, 4.44; $95 \% \mathrm{CI}$, $0.52-38.05 ; p=0.14)$. This increased risk of venous thromboembolic events in the closure arm was possibly caused by the difference in use of anticoagulation in the medical arm compared with the closure arm $(21.6 \%$ vs $3.3 \%$, respectively).

The CLOSE trial (Class II) randomized 663 participants aged 18-59 years with PFO and cryptogenic non-smallvessel stroke and an atrial septal aneurysm and/or large shunt in a 1:1:1 ratio to aspirin, anticoagulation, or PFO closure with any device marked Conformité Européenne. ${ }^{13}$ In total, 11 different devices were used, with the Abbott AMPLATZER PFO Occluder device being the most common (51\%), followed by the Cardia Intrasept PFO Occluder (13\%). In the anticoagulation arm, 93\% of participants received a vitamin $\mathrm{K}$ antagonist. The investigators reported no strokes in the closure group and 14 strokes in the antiplatelet group, for a rate difference of $-0.78 \%$ per year $(95 \% \mathrm{CI},-1.22 \%$ to $-0.43 \%$ per year). The study authors did not provide a statistical comparison between anticoagulation and PFO closure but reported 3 strokes in the anticoagulation group, one of which was a subarachnoid hemorrhage, rate difference $-0.31 \%$ per year (95\% CI, $-0.84 \%$ to $0.01 \%$ ) favoring closure. Procedural complications were reported in 5.9\% (95\% CI, 3.5\%-9.6\%), and non-periprocedural atrial fibrillation occurred more commonly in participants who received 
closure (rate difference $0.76 \%$ per year, $95 \%$ CI, $0.309 \%-1.40 \%$ per year).

The REDUCE trial (Class II) randomized 664 participants with $\mathrm{PFO}$ and embolic-appearing cryptogenic stroke in a 2: 1 ratio to closure with a GORE HELEX Septal Occluder/ CARDIOFORM Septal Occluder or antiplatelet therapy. ${ }^{14}$ After a median 3.2 years of follow-up, recurrent strokes occurred in $1.4 \%$ of the closure arm and in $5.4 \%$ of participants treated with antiplatelet therapy, for a rate difference of $-1.32 \%$ per year ( $95 \% \mathrm{CI},-2.53 \%$ to $-0.43 \%$ per year). Follow-up with MRI at 2 years showed no difference in the rate of new subclinical infarct in a comparison of participants in the closure arm with those in the medical arm, $4.4 \%$ vs $4.5 \%$, respectively (HR 0.98 , $95 \%$ CI, 0.43 to 2.23, $p=0.97)$. Procedural complications occurred in $3.9 \%$ (95\% CI, 2.4\%-6.1\%), and non-periprocedural atrial fibrillation was not different when participants receiving PFO closure were compared with those receiving medical treatment, with a rate difference $0.51 \%$ per year $(95 \% \mathrm{CI}$, $-0.12 \%$ to $1.04 \%)$.

The DEFENSE-PFO trial (Class III), performed at 2 sites in South Korea, randomized 120 participants aged $18-80$ years (mean 52 years) with embolic-appearing cryptogenic stroke and large PFO or with atrial septal aneurysm to closure with the AMPLATZER PFO Occluder (Abbott Medical) or medical therapy consisting of antiplatelet therapy or anticoagulation. ${ }^{15}$ Participants were observed for a median of 2.8 years (interquartile range, 0.9-4.1 years). There were no recurrent strokes in those participants who underwent closure and 5 recurrent strokes in participants treated medically, for a rate difference of $-3.57 \%$ per year $(95 \% \mathrm{CI},-7.42 \%$ to $-0.87 \%)$. Periprocedural complications occurred in $3.3 \%$ (95\% CI, $0.9 \%-11.3 \%)$, and there was no reported nonperiprocedural atrial fibrillation.

\section{Evidence synthesis and summary of effects}

Incorporating all 4 Class II studies into a fixed-effects metaanalysis shows that $\mathrm{PFO}$ closure was associated with a summary HR for recurrent stroke of 0.41 (95\% CI, 0.25-0.67, $\mathrm{I}^{2}=$ $12 \%)$. A random-effects sGS-weighted meta-analysis of these studies yielded a similar summary RR of 0.36 (95\% CI, 0.05-2.58), but the much wider CIs suggest considerable uncertainty regarding the magnitude of the risk reduction. The panel performed sensitivity analyses adding data from CLOSURE I and DEFENSE-PFO, which yielded a similar summary HR for recurrent stroke of 0.48 ( $95 \%$ CI, 0.32-0.73, $\left.\mathrm{I}^{2}=42 \%\right)$ using a fixed-effects model and a similar summary RR of 0.42 (95\% CI, 0.16-1.12) using the sGS-weighted random-effects model. A comparison of varying meta-analytic techniques to pool results also did not substantially affect the effect size estimates.

When the AAN's modified GRADE process was applied, the overall confidence in the evidence for PFO closure efficacy was judged moderate, given the consistent Class II evidence.
Subgroup analyses demonstrated no interactions for benefit of closure based on patient age (dichotomized as $<45$ years vs 45-60 years), presence or absence of atrial septal aneurysm, and medication comparator (antiplatelet vs anticoagulation). There were, however, significant interactions for shunt size and radiographic appearance of the stroke, with no clear benefit of closure in those participants without large shunts (HR 0.9, 95\% CI, 0.5-1.6) or those with small deep strokes (HR 2.3, 95\% CI, 0.4-13.3). The definition of large shunt varied across studies but ranged from identifying $>20-30$ microbubbles in the left atrium within 3 cardiac cycles of seeing opacification of the right atrium.

In the medical arms of the included studies, the pooled (random effects, inverse variance) absolute baseline rate of recurrent stroke was 0.9 recurrent strokes per 100 patientyears (95\% CI, 0.6-1.2). The pooled absolute rate reduction of recurrent stroke from closure was -0.67 strokes per 100 patient-years ( $95 \% \mathrm{CI},-0.9$ to -0.4 ).

Focusing on adverse events, a random-effects meta-analysis of the included studies in the primary analysis finds that PFO closure was associated with a risk of major procedural complications of 3.9\% (95\% CI, 2.3\%-5.7\%). The panel's confidence in the evidence for periprocedural complications associated with closure is moderate because of consistent Class II evidence.

Fixed-effect meta-analyses demonstrated an increased risk of developing any atrial fibrillation, RR 3.12 (95\% CI, 1.71-5.68, $\left.\mathrm{I}^{2}=45 \%\right)$, and study-defined serious non-periprocedural atrial fibrillation, RR 2.72 (95\% CI, 1.30-5.68, $\mathrm{I}^{2}=0 \%$ ) associated with a pooled absolute rate increase of 0.33 cases per 100 patient-years ( $95 \% \mathrm{CI},-0.9$ to -0.4$)$ in participants who received closure compared with those receiving medical treatment. As with the recurrent stroke risk, a random-effects meta-analysis appropriate for low event rates (sGS weighted) highlighted the uncertainty in the estimate of the magnitude of increased risk of serious non-periprocedural atrial fibrillation, RR 2.87 (95\% CI, 0.834-9.872). The rate of non-periprocedural atrial fibrillation was not meaningfully different when the metaanalysis included the CLOSURE I trial. The panel's confidence in the evidence for the increased risk of atrial fibrillation associated with closure is moderate because of consistent Class II evidence.

\section{Conclusions}

For patients with cryptogenic stroke and $\mathrm{PFO}$, percutaneous PFO closure probably reduces the risk of stroke recurrence with an HR of 0.41 (95\% CI, 0.25-0.67, $\left.\mathrm{I}^{2}=12 \%\right)$ and an absolute risk reduction of $3.4 \%$ (95\% CI, $2.0 \%-4.5 \%)$ at 5 years; probably is associated with a periprocedural complication rate of $3.9 \%$ (95\% CI, $2.3 \%-5.7 \%$ ); and probably is associated with the development of serious nonperiprocedural atrial fibrillation, with a relative risk of 2.72 (95\% CI, $1.30-5.68, \mathrm{I}^{2}=0 \%$ ). 


\section{In patients with a PFO who have had a cryptogenic ischemic stroke or TIA, does anticoagulation reduce the risk of stroke recurrence compared with antiplatelet medication?}

\section{Evidence}

The first study was the PFO in Cryptogenic Stroke Study (Class II), a substudy of a larger randomized trial of warfarin vs aspirin in patients with stroke or TIA without atrial fibrillation or extracranial carotid stenosis, in which 630 participants with stroke referred by their clinicians to undergo transesophageal echocardiography (TEE) were randomized to warfarin $(\mathrm{n}=$ 312) or aspirin $(n=318) .{ }^{16}$ Of this cohort, 98 participants were deemed to have had a cryptogenic stroke and had a PFO. In this subgroup, there was no significant difference in recurrent stroke at 2 years between participants given warfarin and those given aspirin, $2 / 42(4.8 \%)$ vs $8 / 56$ (14.3\%), respectively (HR 0.52, $95 \%$ CI, 0.16-1.67). Another small study randomized 47 participants with cryptogenic stroke and PFO to aspirin $240 \mathrm{mg} /$ day $(n=24)$ or dose-adjusted warfarin with target international normalized ratio $2-3(\mathrm{n}=23)$ and observed them for 18 months (Class II, because of unblinded end point ascertainment; participants and their caregivers were unblinded to treatment assignment and actual treatment received). ${ }^{17}$ The results did not provide recurrent stroke rates separate from TIA events. However, they reported no difference in ischemic stroke (5) or TIA (2) events between treatment groups (HR combined stroke and TIA favoring aspirin 3.03, 95\% CI, 0.59-16.7). The CLOSE study ${ }^{13}$ described previously (Class II) included a 3-way randomization between PFO closure, antiplatelet medication, and anticoagulation. There was no significant difference in the stroke recurrence rate among participants given anticoagulation compared with those given antiplatelet therapy, HR 0.44 (95\% CI, 0.11-1.48). Two additional studies compared direct oral anticoagulants (DOACs) to antiplatelet medication in patients with embolic stroke of undetermined source and reported the outcomes separately for patients with PFO. The first is the NAVIGATE-ESUS trial (Class II), which randomized patients to aspirin, $100 \mathrm{mg}$ daily, or rivaroxaban, $15 \mathrm{mg}$ once daily (standard dosing for most stroke prevention in patients with atrial fibrillation is $20 \mathrm{mg}$ once daily). ${ }^{18} \mathrm{~A}$ PFO was detected via either transthoracic echocardiography (TTE) or TEE in 534/7,209 (7.4\%) overall, and there was no significant difference in recurrent stroke risk comparing patients taking rivaroxaban with those taking aspirin, HR 0.54 (95\% CI, 0.22-1.36). Major bleeding risk was likewise not significantly different, HR 2.05 (95\% CI, 0.51-8.18). The RESPECT-ESUS trial (Class II) randomized patients to aspirin, $100 \mathrm{mg}$ daily, or dabigatran, 150 or $110 \mathrm{mg}$ twice daily $(150 \mathrm{mg}$ twice daily is the standard dosing for stroke prevention for most patients with atrial fibrillation) ${ }^{19}$ Overall, $680 / 5,390$ (12.6\%) were found to have a PFO via TTE or TEE, and there was no difference in recurrent stroke risk, HR 0.88 (95\% CI, 0.45-1.71). Major bleeding risks were not presented for the subgroup with PFO, although overall, there was no difference between those given dabigatran and those given aspirin, $\mathrm{RD} 0.5 \%$ ( $95 \% \mathrm{CI},-0.4 \%$ to $1.3 \%$ ). Neither use of TEE nor use of bubble contrast studies was mandated for these studies, likely explaining the relatively low rates of PFO prevalence.

\section{Evidence synthesis and summary of effects}

A random-effects meta-analysis comparing anticoagulation (with warfarin or a DOAC) with aspirin yields a summary HR of 0.73 (95\% CI, 0.45-1.17). Assuming a linear rate of stroke in aspirin-treated patients of $2 \%$ per year and a 5 -year time horizon, this HR corresponds to a number needed to treat of 21 (95\% CI, 19 to -60$)$. With use of the AAN's modified GRADE process, the evidence was anchored at moderate confidence for this question but was then downgraded to low confidence because of imprecision.

\section{Conclusion}

For patients with cryptogenic stroke and PFO, anticoagulation medication and antiplatelet medication are possibly equally effective at reducing recurrent stroke (HR 0.73, 95\% CI, $0.45-1.17$ ). Of note, the high end of the CI does rule out a clinically important benefit for aspirin.

\section{Practice recommendations}

\section{Recommendation 1 rationale}

Ischemic stroke may be caused by a variety of heterogeneous mechanisms, and secondary stroke prevention is optimized by targeting the most likely etiology of the preceding event. ${ }^{20-22}$ An appropriately thorough workup depends on the individual patient and whether a compelling stroke etiology has already been identified. The randomized PFO closure trials all mandated thorough evaluations for participants before enrollment, including CT angiography (CTA) or MR angiography (MRA) of the head and neck vessels in all studies and hypercoagulable screening in many to rule out other stroke mechanisms; moreover, all studies required TEE to characterize the PFO and ensure that it was the most likely etiology for the initial event. There is accumulating evidence that occult atrial fibrillation accounts for a meaningful portion of cryptogenic stroke. ${ }^{23}$ Given that they were designed and initiated before atrial fibrillation monitoring became routine, none of the PFO closure trials required prolonged monitoring before enrollment, although it is important to note that the incidence of atrial fibrillation is strongly correlated with increasing age and is unlikely to occur in patients aged $<50$ years. Other risk factors and biomarkers have been associated with atrial fibrillation and may increase clinical suspicion, including systemic hypertension, obesity, sleep apnea, enlarged left atrium, hyperthyroidism, diabetes, alcohol abuse, cigarette smoking, elevated serum $\mathrm{N}$-terminal pro b-type natriuretic peptide (NT-proBNP), frequent premature atrial contractions, and increased P-wave dispersion on ECG. ${ }^{24,25}$

PFO is highly prevalent, found in approximately $25 \%$ of the general adult population on agitated saline TEE and cadaveric studies. ${ }^{26,27}$ Transcranial Doppler ultrasonography (TCD) has been demonstrated to have similar sensitivity and specificity to 
TEE to detect right-to-left shunting, although TCD does not rule out other cardioembolic sources seen on TEE and cannot confirm that shunting is intracardiac or assess PFO morphology, including anatomic size, location, and length of the tunnel. ${ }^{28}$ Multiple studies have identified an association between PFO and otherwise cryptogenic stroke, with increasing PFO prevalence in younger patients with stroke and those lacking traditional vascular risk factors such as hypertension, hypercholesterolemia, and diabetes. $^{29-31}$

The risk of stroke recurrence in patients with PFO and no other etiology identified is low, approximately $1 \%$ per year while individuals are treated with medication alone. This stroke risk is generally lower than the stroke risk caused by other possible common stroke mechanisms. ${ }^{32}$ Thus, if an alternative plausible higher risk mechanism of stroke is identified, it is likely that the PFO was an innocent bystander.

\section{Statement 1a}

In patients being considered for PFO closure, clinicians should ensure that an appropriately thorough evaluation has been performed to rule out alternative mechanisms of stroke, as was performed in all positive PFO closure trials (level B).

\section{Statement $1 b$}

In patients being considered for PFO closure, clinicians should obtain brain imaging to confirm stroke size and distribution, assessing for an embolic pattern or a lacunar infarct (typically involving a single deep perforator, $<1.5 \mathrm{~cm}$ in diameter) (level B).

\section{Statement $1 c$}

In patients being considered for PFO closure, clinicians should obtain complete vascular imaging (MRA or CTA) of the cervical and intracranial vessels to look for dissection, vasculopathy, and atherosclerosis (level B).

\section{Statement 1d}

In patients being considered for PFO closure, clinicians must perform a baseline ECG to look for atrial fibrillation (level A).

\section{Statement $1 e$}

Select patients being considered for PFO closure thought to be at risk of atrial fibrillation should receive prolonged cardiac monitoring for at least 28 days (level B). Risk factors for atrial fibrillation include age $\geq 50$ years, hypertension, obesity, sleep apnea, enlarged left atrium, elevated NT-proBNP, frequent premature atrial contractions, and increased P-wave dispersion. Recently published guidelines from the American Heart Association, American College of Cardiology, and Heart Rhythm Society recommend prolonged ECG monitoring following cryptogenic stroke for patients older than 40 years, although more research is needed to define the yield in unselected young patients and in patients with PFO. ${ }^{33}$

\section{Statement $1 f$}

In patients being considered for PFO closure, clinicians should assess for cardioembolic sources using TTE followed by TEE assessment if the first study does not identify a high-risk stroke mechanism. Studies should use bubble contrast, with and without Valsalva maneuver, to assess for right-to-left shunt and determine degree of shunting (level B).

\section{Statement $1 \mathrm{~g}$}

In patients being considered for PFO closure, clinicians should perform hypercoagulable studies that would be considered a plausible high-risk stroke mechanism that would lead to a change in management such as requiring lifelong anticoagulation (e.g., persistent moderate- or high-titer antiphospholipid antibodies in a younger patient with cryptogenic stroke) ${ }^{34}$ (level B).

\section{Statement $1 \mathrm{~h}$}

In patients being considered for PFO closure, clinicians may use TCD agitated saline contrast as a screening evaluation for right-to-left shunt, but this does not obviate the need for TTE and TEE to rule out alternative mechanisms of cardio embolism and confirm that right-to-left shunting is intracardiac and transseptal (level C).

\section{Statement $1 i$}

Before undergoing PFO closure, patients should be assessed by a clinician with expertise in stroke to ensure that the PFO is the most plausible mechanism of stroke (level B).

\section{Statement $1 j$}

If a higher risk alternative mechanism of stroke is identified, clinicians should not routinely recommend PFO closure (level B).

\section{Statement $1 k$}

Before undergoing PFO closure, patients should be assessed by a clinician with expertise in assessing the degree of shunting and anatomic features of a PFO, and performing PFO closure, to assess whether the PFO is anatomically appropriate for closure, to ascertain whether other factors are present that could modify the risk of the procedure, and to address postprocedure management (level B).

\section{Statement 11}

In patients with a PFO detected after stroke and no other etiology identified after a thorough evaluation, clinicians should counsel that having a PFO is common; that it occurs in about 1 in 4 adults in the general population; that it is difficult 
to determine with certainty whether their PFO caused their stroke; and that PFO closure probably reduces recurrent stroke risk in select patients (level B).

\section{Recommendation 2 rationale}

Among patients younger than 60 years with no other etiology identified after a thorough diagnostic evaluation, transcatheter PFO closure probably reduces the risk of recurrent stroke (summary rate difference $-0.67 \%$ per year, $95 \% \mathrm{CI},-0.39 \%$ to $-0.94 \%, \mathrm{I}^{2}=0$ ), with a number needed to treat of 29 to reduce 1 stroke at 5 years. PFO closure was associated with a small risk of procedural complications (summary risk 3.9\% [95\% CI, 2.3\%-5.7\%]) and non-periprocedural atrial fibrillation (summary rate difference $0.33 \%$ per year $[95 \% \mathrm{CI}$, $0.04 \%-0.65 \%]$ ), although most of these events were reported to be self-limited and are of uncertain long-term clinical consequence, given the lower rate of stroke in patients whose PFOs were closed. Subgroup analysis suggests that the overall benefit seen across trials may not extend to those patients with small shunts and small, deep infarcts. Clinical studies of PFO closure have characterized PFO size as the greatest degree of right-to-left shunting under different testing states rather than the anatomic size of a PFO because the size of the opening is dynamic. Importantly, some small deep strokes may be caused by embolism, most likely in younger patients without traditional vascular risk factors. Of note, the subgroup analysis also does not demonstrate any benefit interaction for presence or absence of atrial septal aneurysm, despite some studies reporting a larger shunt and higher risk of stroke recurrence if atrial septal aneurysm is present. ${ }^{35,36}$ In addition, the subgroup meta-analysis showed no difference in the benefit of PFO closure in patients aged 45-60 years compared with those aged $<45$ years. Furthermore, there is evidence that PFO may play a role in some cryptogenic stroke in patients older than 60 years, and the DEFENSE-PFO trial included patients older than 60 years. ${ }^{15,30,37}$

\section{Statement $2 a$}

In patients younger than 60 years with a PFO and an embolicappearing infarct and no other mechanism of stroke identified, clinicians may recommend closure following a discussion of potential benefits (reduction of stroke recurrence) and risks (procedural complication and atrial fibrillation) (level C).

\section{Statement $2 b$}

Clinicians may inform patients that presence of a large shunt probably is associated with benefit from closure. Conversely, there probably is less likelihood of benefit in patients with a small shunt or a non-embolic-appearing single, small, deep infarct, and it is uncertain whether atrial septal aneurysm in the absence of a large shunt influences the likelihood of benefitting from PFO closure (level C).

\section{Statement 2c}

PFO closure may be offered in other populations, such as for a patient who is aged 60-65 years with a very limited degree of traditional vascular risk factors (i.e., hypertension, diabetes, hyperlipidemia, or smoking) and no other mechanism of stroke detected following a thorough evaluation, including prolonged monitoring for atrial fibrillation (level C).

\section{Statement 2d}

PFO closure may be offered to younger patients (e.g., <30 years) with a single, small, deep stroke $(<1.5 \mathrm{~cm})$, a large shunt, and absence of any vascular risk factors that would lead to intrinsic small-vessel disease such as hypertension, diabetes, or hyperlipidemia (level C).

\section{Statement $2 e$}

In a patient for whom PFO closure is being considered, a shared decision-making approach between clinicians and the patient should be used, exploring how well the patient's attributes match those included in the positive PFO closure trials and the patient's preferences and concerns regarding risk of stroke recurrence and risk of adverse events (level B).

\section{Recommendation 3 rationale}

All patients with previous stroke should be treated with an antithrombotic medication indefinitely if there is no bleeding contraindication, regardless of whether a PFO is present or if it is closed. $^{20}$ However, specific antithrombotic management for patients with stroke thought to be caused by PFO remains uncertain. Existing randomized studies comparing anticoagulation with antiplatelet therapy do not demonstrate that either treatment regimen is superior ( $\mathrm{HR} 0.73,95 \% \mathrm{CI}, 0.45-1.17$ ). However, the finding that closure of the PFO appears to reduce recurrent stroke risk suggests that paradoxical embolization of a venous thromboembolism is the mechanism for a substantial portion of recurrent strokes. In addition, there is high-level evidence that anticoagulation is superior to antiplatelet medication for venous thromboembolism. ${ }^{38,39}$ The benefit of performing closure in patients being treated with anticoagulation is unclear.

\section{Statement $3 a$}

In patients who opt to receive medical therapy alone without PFO closure, clinicians may recommend either an antiplatelet medication such as aspirin or anticoagulation (using a vitamin $\mathrm{K}$ antagonist, a direct thrombin inhibitor, or a factor $\mathrm{Xa}$ inhibitor) (level C).

\section{Statement $3 b$}

In patients who would otherwise be considered good candidates for PFO closure but require long-term anticoagulation because of suspected or proven hypercoagulability (defined thrombophilia, unprovoked deep venous thrombosis, or unprovoked pulmonary embolism), clinicians should counsel 
the patient that the efficacy of PFO closure in addition to anticoagulation cannot be confirmed or refuted (level B).

\section{Suggestions for future research}

Additional PFO closure devices may be acceptable if they are approved for use following demonstration of similar safety profile and successful closure of right-to-left shunting. DOACs have superior venous thromboembolism treatment and efficacy for stroke prevention in patients with atrial fibrillation. ${ }^{40,41}$ Studies comparing DOACs with PFO closure in younger patients and studies comparing DOACs with antiplatelets in older patients and younger patients not interested in closure are warranted. Studies of PFO and PFO closure in the pediatric stroke population and select patients older than 60 years are also needed. Additional studies are needed to better understand anatomic characteristics that may influence the risk of stroke in patients with PFO. The randomized trials excluded patients with stroke that occurred longer than 6 months previously, and it remains unclear whether closure provides a similar benefit in these patients who otherwise still fit the studies' inclusion criteria. Longterm and large-scale safety registries for patients who have received $\mathrm{PFO}$ closure are needed to assess the risk of device erosion, fracture, embolization, and thrombotic and endocarditis risks and the effect of residual shunts and incidence of atrial fibrillation.

\section{Study funding}

This practice advisory was developed with financial support from the American Academy of Neurology (AAN). The authors who serve as AAN subcommittee members or as methodologists (S.R.M., G.S.G., K.I., and N.S.) were reimbursed by the AAN for expenses related to travel to subcommittee meetings where drafts of manuscripts were reviewed.

\section{Disclosure}

S. Messé has received royalties for articles written for UpToDate, including articles on antiplatelets for secondary stroke prevention, coronary artery bypass graft surgery in patients with cerebrovascular disease, and PFO and stroke; has received support from WL Gore and Associates for the REDUCE PFO closure study, from GlaxoSmithKline for a study of outcomes from proximal aortic surgeries, from Bayer for a study of rivaroxaban for secondary stroke prevention in patients with embolic stroke of undetermined source, from Mallinckrodt for a study of the impact of inhaled nitric oxide on cerebral perfusion, from Novartis for a study of BAF312 in patients with intracerebral hemorrhage (ICH), and from Biogen for a study of glibenclamide for cerebral edema following large hemispheric infarction; received support from the NIH for work with the cardiothoracic surgery network, deferoxamine in $\mathrm{ICH}$, neurologic outcomes in a renal insufficiency cohort; and has provided his expert opinion for medical- legal cases involving stroke. G. Gronseth serves as an associate editor for Neurology; has served as chief evidencebased medicine consultant for the American Academy of Neurology (AAN); and serves as an editorial advisory board member of Brain \& Life. D. Kent serves on the editorial board for Diagnostic and Prognostic Research and has received research and consultant funding from the PatientCentered Outcomes Research Institute (PCORI), NIH, Veterans Administration Health Services, Biogen, and Janssen. J. Kizer reports stock ownership in Amgen, Bristol-Myers Squibb, Gilead Sciences, Johnson \& Johnson, Medtronic, Merck, and Pfizer; has served as editor of the Clinical Trials and Their Interpretation section of Current Atherosclerosis Reports; has received research support from the NIH (National Heart, Lung, and Blood Institute, National Institute on Aging, and National Institute of Allergy and Infectious Diseases) and PCORI; and has given expert witness consultation for a legal case involving hypertension management. S. Homma served on the data and safety monitoring board for the RESPECT trial; has received funding for travel from the American College of Cardiology; and has received research support from the $\mathrm{NIH}$ and the University of South Florida. L. Rosterman has received honoraria for a lecture on acute stroke management for rural outreach. J. Carroll serves on the Society of Cardiac Angiography and Intervention's Writing Committee for Operator and Institutional Requirements for PFO Closure; has been on the steering committee for the RESPECT trial, with sponsors including Abbott Vascular, AGA Medical, and St. Jude Medical; has received funding for travel for RESPECT Steering Committee responsibility; holds a patent for 3D coronary reconstruction software-licensed by Phillips Medical; receives honoraria from grand rounds at various academic institutions; performs PFO closure approximately (3-5 PFO closures per month); has received research support from the Steering Committee of RESPECT trial and Steering Committee of AMULET trial (LAA Occlusion); receives license fee payments related to $3 \mathrm{D}$ coronary imaging software; receives royalty payments or has contractual rights for receipt of future royalty payments for $3 \mathrm{D}$ coronary imaging software; serves as a member of the editorial board for Circulation: Cardiovascular Interventions and the journals of the Society for Cardiovascular Angiography and Interventions; receives royalties for publishing from Structural Heart Disease Interventions (coedited textbook) and UpToDate (section on mitral valvuloplasty); and has provided consultation for a legal firm defending suits related to alleged inappropriate use of PFO closure by an individual physician. $\mathrm{K}$. Ishida has received royalties for articles written for UpToDate, including articles on blood biomarkers for stroke and medical complications of stroke, prevention and treatment of venous thromboembolism in patients with acute stroke, and medical complications of stroke, and has received funding for travel from the AAN. $\mathrm{N}$. Sangha has received travel reimbursement from the AAN. S. Kasner served as principal investigator for the REDUCE trial 
(WL Gore); serves as a consultant to Medtronic; served on a trial steering committee for Bayer; served on an endpoint adjudication committee for AbbVie; serves on a trial steering committee for Bristol-Myers Squibb; served on a scientific advisory board for Boehringer Ingelheim; has received funding for travel from WL Gore \& Associates and Bayer; has received research support from WL Gore \& Associates, Bayer, Acorda, Medtronic, and the NIH; is a member of the editorial boards of UpToDate, Stroke, Journal of Stroke and Cerebrovascular Diseases, and Practical Neurology; receives publishing royalties from UpToDate; and has given expert testimony in medical-legal proceedings. Go to Neurology.org/ $\mathrm{N}$ for full disclosures.

\section{Disclaimer}

Clinical practice guidelines, practice advisories, systematic reviews, and other guidance published by the American Academy of Neurology (AAN) and its affiliates are assessments of current scientific and clinical information provided as an educational service. The information (1) should not be considered inclusive of all proper treatments methods of care or as a statement of the standard of care; (2) is not continually updated and may not reflect the most recent evidence (new evidence may emerge between the time information is developed and when it is published or read); (3) addresses only the question(s) specifically identified; (4) does not mandate any particular course of medical care; and (5) is not intended to substitute for the independent professional judgment of the treating provider, as the information does not account for individual variation among patients. In all cases, the selected course of action should be considered by the treating provider in the context of treating the individual patient. Use of the information is voluntary. The AAN provides this information on an "as is" basis and makes no warranty, expressed or implied, regarding the information. The AAN specifically disclaims any warranties of merchantability or fitness for a particular use or purpose. The AAN assumes no responsibility for any injury or damage to persons or property arising out of or related to any use of this information or for any errors or omissions.

\section{Conflict of interest}

The American Academy of Neurology (AAN) is committed to producing independent, critical, and trustworthy clinical practice guidelines (CPGs) and evidence-based documents. Significant efforts are made to minimize the potential for conflicts of interest to influence the recommendations of this evidence-based document. Management and disclosure of document developer relationships is conducted in compliance with the 2017 AAN process manual section titled, "Implementing the AAN Conflict of Interest Policy for Guidelines and Case Definitions," which can be viewed at aan.com. ${ }^{2}$

\section{Publication history}

Received by Neurology October 24, 2019. Accepted in final form March 6, 2020.

\section{Appendix Authors}

\begin{tabular}{|c|c|c|}
\hline Name & Location & Contribution \\
\hline $\begin{array}{l}\text { Steven R. } \\
\text { Messé, MD }\end{array}$ & $\begin{array}{l}\text { Department of Neurology, } \\
\text { University of Pennsylvania } \\
\text { School of Medicine, PA }\end{array}$ & $\begin{array}{l}\text { Study concept and design, } \\
\text { acquisition of data, analysis } \\
\text { or interpretation of data, } \\
\text { drafting/revising the } \\
\text { manuscript, critical revision } \\
\text { of the manuscript for } \\
\text { important intellectual } \\
\text { content, and study } \\
\text { supervision }\end{array}$ \\
\hline
\end{tabular}

\begin{tabular}{ll}
\hline Gary S. & Department of Neurology, \\
Gronseth, & University of Kansas \\
MD & Medical Center, MO
\end{tabular}

Study concept and design, acquisition of data, analysis or interpretation of data, revising the manuscript, critical revision of the manuscript for important intellectual content, and study supervision

\begin{tabular}{lll}
\hline David M. & Institute for Clinical & Critical revision of the \\
Kent, MD, & Research and Health Policy & manuscript for important \\
MSc & Studies, Tufts University & intellectual content \\
& $\begin{array}{l}\text { School of Medicine, } \\
\text { Boston, MA }\end{array}$
\end{tabular}

\begin{tabular}{|c|c|c|}
\hline $\begin{array}{l}\text { Jorge R. } \\
\text { Kizer, MD, } \\
\text { MSc }\end{array}$ & $\begin{array}{l}\text { San Francisco Veterans } \\
\text { Affairs Health Care System } \\
\text { and University of California } \\
\text { San Francisco, CA }\end{array}$ & $\begin{array}{l}\text { Critical revision of the } \\
\text { manuscript for important } \\
\text { intellectual content }\end{array}$ \\
\hline $\begin{array}{l}\text { Shunichi } \\
\text { Homma, } \\
\text { MD }\end{array}$ & $\begin{array}{l}\text { Division of Cardiology, } \\
\text { Columbia University } \\
\text { Medical Center, New York }\end{array}$ & $\begin{array}{l}\text { Critical revision of the } \\
\text { manuscript for important } \\
\text { intellectual content }\end{array}$ \\
\hline $\begin{array}{l}\text { Lee } \\
\text { Rosterman, } \\
\text { DO }\end{array}$ & $\begin{array}{l}\text { Department of Neurology, } \\
\text { University of Kansas } \\
\text { Medical Center, MO }\end{array}$ & $\begin{array}{l}\text { Critical revision of the } \\
\text { manuscript for important } \\
\text { intellectual content }\end{array}$ \\
\hline $\begin{array}{l}\text { John D. } \\
\text { Carroll, MD }\end{array}$ & $\begin{array}{l}\text { Department of Medicine } \\
\text { (Cardiology), University of } \\
\text { Colorado School of } \\
\text { Medicine, Aurora }\end{array}$ & $\begin{array}{l}\text { Critical revision of the } \\
\text { manuscript for important } \\
\text { intellectual content }\end{array}$ \\
\hline $\begin{array}{l}\text { Koto Ishida, } \\
\text { MD }\end{array}$ & $\begin{array}{l}\text { Department of Neurology, } \\
\text { New York University }\end{array}$ & $\begin{array}{l}\text { Critical revision of the } \\
\text { manuscript for important } \\
\text { intellectual content }\end{array}$ \\
\hline $\begin{array}{l}\text { Navdeep } \\
\text { Sangha, MD }\end{array}$ & $\begin{array}{l}\text { Department of Neurology, } \\
\text { Kaiser Permanente, Los } \\
\text { Angeles, CA }\end{array}$ & $\begin{array}{l}\text { Critical revision of the } \\
\text { manuscript for important } \\
\text { intellectual content }\end{array}$ \\
\hline $\begin{array}{l}\text { Scott E. } \\
\text { Kasner, MD, } \\
\text { MSCE }\end{array}$ & $\begin{array}{l}\text { Department of Neurology, } \\
\text { University of Pennsylvania } \\
\text { School of Medicine, } \\
\text { Philadelphia }\end{array}$ & $\begin{array}{l}\text { Critical revision of the } \\
\text { manuscript for important } \\
\text { intellectual content and } \\
\text { study supervision }\end{array}$ \\
\hline
\end{tabular}

\section{References}

1. Messé SR, Gronseth G, Kent DM, et al. Practice advisory: recurrent stroke with patent foramen ovale (update of practice parameter): Report of the Guideline Development, Dissemination, and Implementation Subcommittee of the American Academy of Neurology. Neurology 2016;87:815-821.

2. Gronseth GS, Cox J, Gloss D, et al. Clinical Practice Guideline Process Manual. Minneapolis, MN: The American Academy of Neurology; 2017.

3. Efthimiou O. Practical guide to the meta-analysis of rare events. Evid Based Ment Health 2018;21:72-76.

4. Guolo A, Varin C. Random-effects meta-analysis: the number of studies matters. Stat Methods Med Res 2017;26:1500-1518.

5. Higgins JP, Thompson SG, Spiegelhalter DJ. A re-evaluation of random-effects metaanalysis. J R Stat Soc Ser A Stat Soc 2009;172:137-159.

6. Shuster JJ, Guo JD, Skyler JS. Meta-analysis of safety for low event-rate binomial trials. Res Synth Methods 2012;3:30-50.

7. Guyatt GH, Oxman AD, Schünemann HJ, Tugwell P, Knottnerus A. GRADE guidelines: a new series of articles in the Journal of Clinical Epidemiology. J Clin Epidemiol 2011;64:380-382. 
8. Guyatt GH, Oxman AD, Sultan S, et al. GRADE guidelines: 9. Rating up the quality of evidence. J Clin Epidemiol 2011;64:1311-1316.

9. Furlan AJ, Reisman M, Massaro J, et al. Closure or medical therapy for cryptogenic stroke with patent foramen ovale. N Engl J Med 2012;366:991-999.

10. Meier B, Kalesan B, Mattle HP, et al. Percutaneous closure of patent foramen ovale in cryptogenic embolism. N Engl J Med 2013;368:1083-1091.

11. Carroll JD, Saver JL, Thaler DE, et al. Closure of patent foramen ovale versus medical therapy after cryptogenic stroke. N Engl J Med 2013;368:1092-1100.

12. Saver JL, Carroll JD, Thaler DE, et al. Long-term outcomes of patent foramen ovale closure or medical therapy after stroke. N Engl J Med 2017;377:1022-1032.

13. Mas JL, Derumeaux G, Guillon B, et al. Patent foramen ovale closure or anticoagulation vs. antiplatelets after stroke. N Engl J Med 2017;377:1011-1021.

14. Sondergaard L, Kasner SE, Rhodes JF, et al. Patent foramen ovale closure or antiplatelet therapy for cryptogenic stroke. N Engl J Med 2017;377:1033-1042.

15. Lee PH, Song JK, Kim JS, et al. Cryptogenic stroke and high-risk patent foramen ovale: the DEFENSE-PFO trial. J Am Coll Cardiol 2018;71:2335-2342.

16. Homma S, Sacco RL, Di Tullio MR, Sciacca RR, Mohr JP. Effect of medical treatment in stroke patients with patent foramen ovale: patent foramen ovale in Cryptogenic Stroke Study. Circulation 2002;105:2625-2631.

17. Shariat A, Yaghoubi E, Farazdaghi M, Aghasadeghi K, Borhani Haghighi A. Comparison of medical treatments in cryptogenic stroke patients with patent foramen ovale: a randomized clinical trial. J Res Med Sci 2013;18:94-98.

18. Kasner SE, Swaminathan B, Lavados P, et al. Rivaroxaban or aspirin for patent foramen ovale and embolic stroke of undetermined source: a prespecified subgroup analysis from the NAVIGATE ESUS trial. Lancet Neurol 2018;17: 1053-1060.

19. Diener HC, Sacco RL, Easton JD, et al. Dabigatran for prevention of stroke after embolic stroke of undetermined source. N Engl J Med 2019;380:1906-1917.

20. Kernan WN, Ovbiagele B, Black HR, et al. Guidelines for the prevention of stroke in patients with stroke and transient ischemic attack: a guideline for healthcare professionals from the American Heart Association/American Stroke Association. Stroke 2014;45:2160-2236.

21. Culebras A, Messé SR. Summary of evidence-based guideline update: prevention of stroke in nonvalvular atrial fibrillation: report of the Guideline Development Subcommittee of the American Academy of Neurology. Neurology 2014;83:1220.

22. Chaturvedi S, Bruno A, Feasby T, et al. Carotid endarterectomy - an evidence-based review: report of the Therapeutics and Technology Assessment Subcommittee of the American Academy of Neurology. Neurology 2005;65:794-801.

23. Sanna T, Diener HC, Passman RS, et al. Cryptogenic stroke and underlying atrial fibrillation. N Engl J Med 2014;370:2478-2486.

24. Thijs V. Atrial fibrillation detection: fishing for an irregular heartbeat before and after stroke. Stroke 2017;48:2671-2677.

25. January CT, Wann LS, Calkins H, et al. 2014 AHA/ACC/HRS guideline for the management of patients with atrial fibrillation: a report of the American College of Cardiology/American Heart Association Task Force on practice guidelines and the Heart Rhythm Society. Circulation 2014;130:e199-e267.
26. Meissner I, Whisnant JP, Khandheria BK, et al. Prevalence of potential risk factors for stroke assessed by transesophageal echocardiography and carotid ultrasonography: the SPARC study. Stroke prevention: assessment of risk in a community. Mayo Clin Proc 1999; 74:862-869.

27. Hagen PT, Scholz DG, Edwards WD. Incidence and size of patent foramen ovale during the first 10 decades of life: an autopsy study of 965 normal hearts. Mayo Clin Proc 1984;59:17-20.

28. Katsanos AH, Psaltopoulou T, Sergentanis TN, et al. Transcranial Doppler versus transthoracic echocardiography for the detection of patent foramen ovale in patients with cryptogenic cerebral ischemia: a systematic review and diagnostic test accuracy meta-analysis. Ann Neurol 2016;79:625-635.

29. Overell JR, Bone I, Lees KR. Interatrial septal abnormalities and stroke: a metaanalysis of case-control studies. Neurology 2000;55:1172-1179.

30. Handke M, Harloff A, Olschewski M, Hetzel A, Geibel A. Patent foramen ovale and cryptogenic stroke in older patients. N Engl J Med 2007;357:2262-2268.

31. Kent DM, Ruthazer R, Weimar C, et al. An index to identify stroke-related vs incidental patent foramen ovale in cryptogenic stroke. Neurology 2013;81:619-625.

32. Amarenco P, Lavallée PC, Labreuche J, et al. One-year risk of stroke after transient ischemic attack or minor stroke. N Engl J Med 2016;374:1533-1542.

33. January CT, Wann LS, Calkins H, et al. 2019 AHA/ACC/HRS focused update of the 2014 AHA/ACC/HRS guideline for the management of patients with strial fibrillation: a report of the American College of Cardiology/American Heart Association Task Force on Clinical Practice Guidelines and the Heart Rhythm Society. Heart Rhythm 2019;16:e66-e93.

34. Tektonidou MG, Andreoli L, Limper M, et al. EULAR recommendations for the management of antiphospholipid syndrome in adults. Ann Rheum Dis 2019;78:1296-1304.

35. Snijder RJ, Luermans JG, de Heij AH, et al. Patent foramen ovale with atrial septal aneurysm is strongly associated with migraine with aura: a large observational study. J Am Heart Assoc 2016;5:e003771.

36. Mas JL, Arquizan C, Lamy C, et al. Recurrent cerebrovascular events associated with patent foramen ovale, atrial septal aneurysm, or both. N Engl J Med 2001;345: $1740-1746$.

37. Mazzucco S, Li L, Binney L, Rothwell PM. For the Oxford Vascular Study Phenotyped Cohort. Prevalence of patent foramen ovale in cryptogenic transient ischaemic attack and non-disabling stroke at older ages: a population-based study, systematic review, and meta-analysis. Lancet Neurol 2018;17:609-617.

38. Castellucci LA, Cameron C, Le Gal G, et al. Efficacy and safety outcomes of oral anticoagulants and antiplatelet drugs in the secondary prevention of venous thromboembolism: systematic review and network meta-analysis. BMJ 2013;347:f5133.

39. Weitz JI, Lensing AWA, Prins MH, et al. Rivaroxaban or aspirin for extended treatment of venous thromboembolism. N Engl J Med 2017;376:1211-1222.

40. Cohen AT, Harrington RA, Goldhaber SZ, et al. Extended thromboprophylaxis with betrixaban in acutely ill medical patients. N Engl J Med 2016;375:534-544.

41. López-López JA, Sterne JAC, Thom HHZ, et al. Oral anticoagulants for prevention of stroke in atrial fibrillation: systematic review, network meta-analysis, and cost effectiveness analysis. BMJ 2017;359:j5058.

\section{AAN Online Learning}

Browse a variety of online CME, self-assessment, and other learning activities to suit your wide-ranging interests and learning styles. Visit AAN.com/Learn.

\section{Get Quick, Convenient Updates with NeuroBytes}

Convenient 3- to 6-minute NeuroBytes videos address timely and relevant topics in neurology, along with additional resources for further self-guided exploration - and are free to AAN members! Browse the full catalog of videos and subscribe today. Visit AAN.com/view/NeuroBytes today! 


\section{Neurology}

\section{Practice advisory update summary: Patent foramen ovale and secondary stroke prevention: Report of the Guideline Subcommittee of the American Academy of Neurology}

Steven R. Messé, Gary S. Gronseth, David M. Kent, et al.

Neurology 2020;94;876-885 Published Online before print April 29, 2020

DOI 10.1212/WNL.0000000000009443

This information is current as of April 29, 2020

\section{Updated Information \& Services}

References

Citations

Subspecialty Collections

Permissions \& Licensing

Reprints including high resolution figures, can be found at: http://n.neurology.org/content/94/20/876.full

This article cites 40 articles, 15 of which you can access for free at: http://n.neurology.org/content/94/20/876.full\#ref-list-1

This article has been cited by 1 HighWire-hosted articles: http://n.neurology.org/content/94/20/876.full\#\#otherarticles

This article, along with others on similar topics, appears in the following collection(s):

\section{Cardiac}

http://n.neurology.org/cgi/collection/cardiac

Childhood stroke

http://n.neurology.org/cgi/collection/childhood_stroke

Stroke in young adults

http://n.neurology.org/cgi/collection/stroke_in_young_adults

Stroke prevention

http://n.neurology.org/cgi/collection/stroke_prevention

Information about reproducing this article in parts (figures,tables) or in its entirety can be found online at:

http://www.neurology.org/about/about_the_journal\#permissions

Information about ordering reprints can be found online:

http://n.neurology.org/subscribers/advertise

Neurology ${ }^{\circledR}$ is the official journal of the American Academy of Neurology. Published continuously since 1951, it is now a weekly with 48 issues per year. Copyright () 2020 American Academy of Neurology. All rights reserved. Print ISSN: 0028-3878. Online ISSN: 1526-632X.

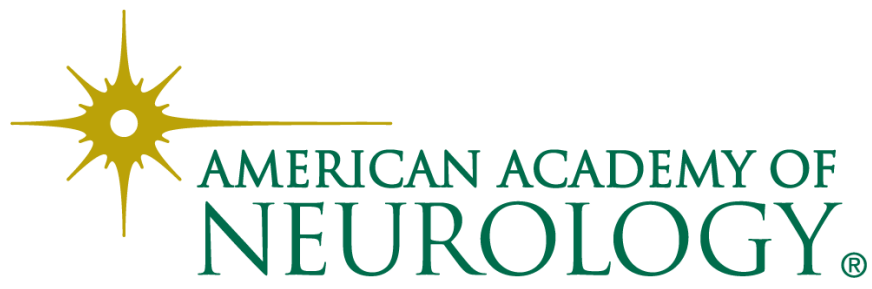

